\title{
Against the Grain
}

Volume 23 | Issue 5

Article 18

November 2011

\section{ATG Interviews Stephen Rhind-Tutt}

Tom Gilson

Against the Grain, gilsont@cofc.edu

Katina Strauch

Against the Grain, kstrauch@comcast.net

Follow this and additional works at: https://docs.lib.purdue.edu/atg

Part of the Library and Information Science Commons

\section{Recommended Citation}

Gilson, Tom and Strauch, Katina (2011) "ATG Interviews Stephen Rhind-Tutt," Against the Grain: Vol. 23: Iss. 5, Article 18. DOI: https://doi.org/10.7771/2380-176X.5992

This document has been made available through Purdue e-Pubs, a service of the Purdue University Libraries. Please contact epubs@purdue.edu for additional information. 
imagine how that opens eBooks to use? The ability to search within books just as you would search a journal article, all within a sweep of the breadth of the library's collection, is a big leap forward in responding to user needs.

ATG: On an even broader scale, how will all of this work with Serials Solutions, web-scale management solution, which is currently in development?

KS: We've talked a bit about the extraordinary research environment that's being built by ProQuest, and that effort is being supported with services that enable libraries to manage their resources, particularly the growing dominance of e-content. Serials Solutions' comprehensive knowledgebase is the core of support across the entire continuum of library services - from improving access and use of collections to easing librarian workloads, and ultimately to reducing operating costs. The new web-scale management solution is aimed at redefining how libraries manage operations, eventually eliminating the need for the ILS as we know it today. It will be a single, unified management solution for libraries that frees staff from low-value tasks and enables them to do the real work of librarians. In the broadest sense, webscale management supports the researcher because it supports the library workflow - the researcher's key partner.

ATG: Are there any new developments that you feel at liberty to give ATG a scoop on?

KS: Sure, we always have some interesting next-steps up our sleeves. We mentioned new products that will integrate ProQuest content with ebrary's research tools. We're really excited to see what researchers can do when they're armed with journal and newspaper content powered by InfoTools and DASH!. And more, watch for a mobile app for ebrary. Students will be able to work with eBooks right in the classroom from their smartphones. That's a powerful way to embed research right in the workflow. I guess from the students perspective it's also good cover when they want to update their Facebook status in class.

TB: The ProQuest research environment is going to bring users in further with capabilities that allow for content creation. We're already exploring this with some of our vertical social networks, such as EEBO Interactions. We have scholars submitting updates to the database that are vetted by an advisory board of other scholars. This process allows for continual improvements and expansion that are directed by the user.

ATG: Thank you both for taking the time to talk to us. We appreciate your thoughtful responses to our questions.

\title{
President, Alexander Street Press, LLC
}

\author{
by Tom Gilson (Associate Editor, Against the Grain) < gilsont@cofc.edu>
}

and Katina Strauch (Editor, Against the Grain) <kstrauch@comcast.net>

ATG: If we're not mistaken you got your start in electronic publishing with Gale and then with Chadwyck-Healey. Can you tell us a little bit about that?

SR-T: I began my publishing career at Abt Books, an offshoot of Abt Associates, one of the world's largest consulting companies. Clark Abt, the founder, believed that CD-ROM had the potential substantially to help the developing world because it would allow for easy dissemination of Western knowledge. I found that more inspiring than selling Hellman's Mayonnaise - which is what I'd been doing previously! We produced some pretty varied CD-ROMs that were ahead of their time (the National Portrait Gallery, a multimedia criminal justice database, and real estate data sets).

From there I was lucky enough to work at SilverPlatter (then the largest vendor of $\mathrm{CD}-\mathrm{ROM}$ in the world), where I ran their Health Sciences division, on to IAC (now Gale), and thence to Chadwyck-Healey (now ProQuest). I've always published for libraries.

ATG: What gave you the inspiration to start Alexander Street Press? What were your first products like?

SR-T: I'd learned the value of controlled vocabularies at SilverPlatter and the value of full text at Chadwyck-Healey. I thought they could be put together far more effectively. I'd been reading Tim Berners-Lee about the semantic Web and Ted Nelson about the deficiencies of HTML and TCP/IP. It was the height of the dot-com era and everyone was trying to get rid of human intelligence. I thought we might go in the opposite direction and use librarian cataloging skills to build semantic tags

I realized that letters and diaries were in essence personal snapshots in place and time - and that with semantic indexing they'd become much more useful. ${ }^{1}$ And so I had the idea for a large collection of letters and diaries, indexed so that you could see what was written in a particular place at a particular time. North American Women's Letters and Diaries was our first product - it had important content, unavailable elsewhere in electronic form, with unique functionality and lots of input from librarians. We've tried to keep to that recipe ever since.

ATG: Since starting the company, you have expanded and now offer a variety of media to the library community. Was that in the plan all along? Or has it been a process of adjusting and taking advantage of new opportunities? Have there been any surprises along the way that have caused you to adjust or change course?

SR-T: There were big surprises. I didn't see Google Books coming - I thought libraries would do that themselves. I didn't think discovery services would get such traction. But in both cases we've adjusted - by publishing much more rare, hard-to-find and in-copyright material and through alliances with the discovery service vendors. In almost all cases we've stayed true to our mission. Our goal has always been to provide the best we can within disciplines. Video performances were a natural extension of drama texts. Oral histories were a natural extension of letters and diaries. When we acquired Classical.com it became evident how we might do this at scale.

ATG: Up to this point Alexander Street Press has focused on the humanities and social sciences but with your new product Nursing Education in Video you seem to be branching out into the sciences. Is this something we should continue to expect?

SR-T: Absolutely. Expect titles in business, law, architecture, medicine, and many other areas. We like to enter new disciplines with a must-have landmark collection. There's been a lack of large, definitive, well-indexed video collections for libraries, so that provides us an entrée into many new disciplines.

ATG: What elements go into your decisionmaking process when you decide to bring a new product to market?

SR-T: Simply put, our mission is "to make silent voices heard." This is a way of saying that we look for content and voices that need to be amplified and made public. A good electronic publisher also looks for ways to add functional value by making these content and voices easier to discover, analyze, annotate, search, and understand.

We aim to stay within specific disciplines because that lets us understand and respond more effectively to what academics and librarians need. We think that librarians already have an abundance of choices, so we try not to duplicate resources that are already out there. This is what leads us to collections as disparate as Underground and Independent Comics, Counseling and Psychotherapy Transcripts, and Nursing Education in Video.

Librarians are essential in this work. They've suggested and helped us find rare material, whether it's unusual newsreels or previously unpublished drama.

ATG: You are an advocate of semantic indexing over traditional forms of indexing. Can you explain the difference? Is semantic indexing used in Alexander Street Press databases? How does it benefit users?

SR-T: Semantic indexing has a broad range of meanings. My preferred definition is to tag "the conceptual content of a body of text by establishing associations between those terms that occur in similar contexts."

It's much more than a fancy way to describe subject indexing. It includes the addition of

continued on page 64 
Interview - Stephen Rhind-Tutt

from page 62

metadata about those subjects. As an example, it's not just tagging content for occurrences of a particular battle, it allows one to say: "Give me all battles in which more than 1,000 people were killed." Or, "Give me documents written by women under the age of 20 that talk about marriage." Or, "What Phase 2 clinical trials of ACE inhibitors have been successful in the past 2 years?" The benefit to users is that it allows richer reference.

This Scientific American article ${ }^{3}$ on the Web does a better job than I of describing the importance of the concepts behind it.

ATG: Last year at the Charleston Conference you dared the audience to "imagine ... that for each term within a discipline there was a page on the web that organized all of the surrounding content for a particular subject within a discipline." You also said that is what you were aiming for at Alexander Street Press - and that you were close to achieving it for music and drama. What would such a page look like and have you achieved it in your databases?

SR-T: Yes, we're aiming for this. We're relatively far down the tracks in music, less so in drama. I don't think that such pages necessarily need to be controlled by Alexander Street. What's exciting to me at the moment are initiatives that allow third party content to be easily linked. To this end we've just spent much of the past year developing an Alexander Street Metadata Repository that will allow third parties to link to any and all of our content. Commercial and non-profit organizations alike will be able to build reference pages and links directly into our content, and to have those pages update easily and at a low cost.

ATG: Pricing is always an issue. We hear from librarians that they are impressed with your innovative and valuable products but that the prices are too steep - especially from the perspective of small-and medium-size libraries. Is there any fairness to that perception?

SR-T: I think it's an outdated perception. Philosophically, our approach has always been to price to allow broad access - we've always had lower prices for smaller institutions.

I'm sure every vendor thinks that it offers good value - so what I've tried to do below is give you some objective comparisons. Perhaps the greatest proof that we're pricing fairly is that many partners license to us, and despite tough economic times our products are selling well to libraries.

Practically, I think the easiest way to show this is in examples: American History in Video has approximately 5,000 video titles in it and academic subscription prices range from $\$ 1,100$ to $\$ 2,500$ depending on the type and size of the institution. The Music Online listening package contains the equivalent of more than 58,000 CDs and costs from $\$ 1,950$ to $\$ 12,495$ for an entire university to subscribe to for a year. The same content on iTunes would cost a single professor $\$ 700,000$ to buy, and that's without all the tools and searchability we provide.

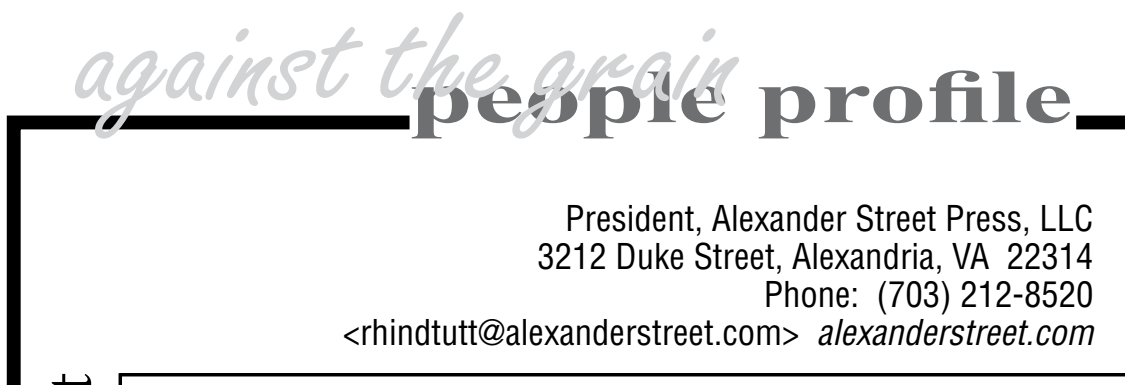

BORN AND LIVED: Windsor, England. Lived in London, Belgium, Germany, Boston, San Francisco, and Washington, DC.

EARLY LIFE: Boarding school in the UK, studied English Literature at UCL, salesperson for Hellman's Mayonnaise, brand manager for Frank Cooper's marmalades, changed to the information industry.

PROFESSIONAL CAREER AND ACTIVITIES: Early employee at SilverPlatter, led health science division; was Director of Product Management for IAC (now Gale); then President of Chadwyck-Healey (U.S.) before founding Alexander Street Press. Currently sit on the boards of the Council for Library and Information Resources (CLIR) and the University of California Press.

FAMILY: Janice (spouse), Michael (8), David (5), Serafina (2).

IN MY SPARE TIME: Resting, TV, reading, movies, Mayan culture, Polar Exploration, history of technology.

FAVORITE BOOKS: The Cat in the Hat, Empire of Sound, Songs of Innocence and Experience, Flight 714, Meet Mr. Mulliner - too many to mention!

PET PEEVES: Accelerate, don't slow down when you merge in traffic. Use of the word "try" in company reports as in: "try to get this sorted out next week."

PHILOSOPHY: "Do it with all thy might."

MOST MEMORABLE CAREER ACHIEVEMENT: Still to come.

GOAL I HOPE TO ACHIEVE FIVE YEARS FROM NOW: I'd really like Alexander Street to fulfill its potential. That's not to make it a huge company - rather it's to have it publish some really long-lasting, landmark collections that stand the test of time. I'd just love to have created publications like the Dictionary of Literary Biography or the Grove Dictionary of Music.

HOW/WHERE DO I SEE THE INDUSTRY IN FIVE YEARS: I'm not sure about everything that will happen in five years, but I am sure this will happen: All content of lasting value will be online. All of it will be accessible via phone, tablet. It will be integrated with DOI-like links. We'll have stopped arguing about whether free or for-fee is the best model and realize that we have to have both. We'll have automated tools that help us analyze the vast body of information at our fingertips, and software that helps us understand it better. Libraries and publishers that have embraced the future and focused on what they can best do for patrons will thrive.

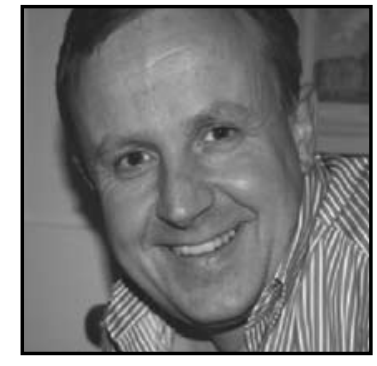

We do offer the ability to purchase content - and this costs more. But again I don't think it's excessive to ask for $\$ 15,000$ to $\$ 30,000$ for our Filmakers Library - that's $\$ 13$ to $\$ 26$ per title for titles that sell for hundreds of dollars each.

ATG: Can libraries customize selections from your databases and come up with a mix that is more affordable? For example, will this type of flexibility be available with your new integrated online repository of academic video titles that is available via the new platform, Academic Video Online?

SR-T: The documentaries - from our Filmakers Library imprint and the counseling and therapy videos from our Microtraining Associates imprint are available as single-streaming titles for $\$ 200$ to $\$ 300$ individually. We're in the process of securing licenses to sell more titles like this. However, for some of our collections the original licensors will not give us single-title rights, and even when they do, they're naturally concerned about losing money if we discount too heavily. So by far and away, the best value for libraries is through our collections.

ATG: While most of your recent offerings have been audio and/or video collections, you are releasing a new database called Anthropology Online that will focus on primary sources like written ethnographies, field notes, seminal texts, memoirs, etc. However, it will be cross-searchable with your Ethnographic Video Online collection. Is this the wave of the future? Can text-only resources stand alone, or do today's scholars expect access to multimedia resources?

continued on page 66 
Interview - Stephen Rhind-Tutt

from page 64

SR-T: Yes, text-only resources can stand alone. In 2012, we plan to launch not just Anthropology Online, but new non-video collections in gay and lesbian studies, additional classical scores, and more history titles.

Having said that, the market is clearly headed towards a media-agnostic future. This will be determined not by the ease with which a publisher can cope with media (as it is today), but by what serves the patron best. And of course, we want to make all our collections cross-searchable within a discipline - as we're doing in anthropology.

I think many see multimedia as a way to "sex up" texts. Often this is a mistake. Adding a few public-domain newsreels to a history book is only a starting point. It's like adding a few fulltext journal articles at the end of an encyclopedia entry. It's more exciting to allow every student to see relevant sections from multiple newsreels for every person, event, and place from the past 100 years. And the right way for that to happen is for us to have DOI-like standards that enable both stand-alone and integrated resources to interact with each other.

ATG: Without divulging any trade secrets, can you tell us what other future developments we can expect from Alexander Street Press?

SR-T: We're really engaged in developing Academic Video Online at the moment. We've set ourselves a goal of having 22,000 high-quality video titles in 25 collections by the end of 2012 - about twice what we have currently. That's a low number in comparison to eBooks, but for video that's, well, vast. We'll make 20,000 of those titles available as a single package, which, for obvious reasons, we're calling the VAST package.

We're also about to launch our metadata repository. As I mention above this is a big deal for us because it will enable others more easily to capitalize on our work. For libraries it will make it possible to develop subject oriented perma-links that avoid our interfaces and drop you directly into the subject, person, place, or object you're interested in.

ATG: Stephen, we want to thank you for taking the time out of your busy schedule to answer our questions. We very much appreciate it.

\section{Endnotes}

1. S. Deerwester, et al, "Improving Information Retrieval with Latent Semantic Indexing," Proceedings of the 51st Annual Meeting of the American Society for Information Science 25 (1988), 36-40.

2. Tim Berners-Lee, James Hendler, and Ora Lassila, "The Semantic Web," Scientific American Magazine, May 17, 2001, http://www.scientificamerican.com/ article.cfm?id=the-semantic-web. Accessed March 26, 2008

3. H. Hedden, "How Semantic Tagging Increases Findability," E-Content Magazine, October 2008, http://www.hedden-information.com/SemanticTagging.pdf. Accessed August 26, 2011.

Book Reviews — M Monographic MLusings

Column Editor: Debbie Vaughn (College of Charleston) < vaughnd@cofc.edu>

Column Editor's Note: This month, two highly distinguished library professionals grace the column inches of Monographic Musings.

ATG readers undoubtedly recognize Bryan M. Carson as the editor of the über-informative and timely Legally Speaking. He is a lawyer, a librarian, and a doctor (of education, that is). Bryan earned his JD from the University of Toledo, his MLIS from the University of Michigan, and his EdD in Higher Education Leadership and Policy from Vanderbilt University. For over a decade, he has shared his expertise and knowledge in multiple positions at the Western Kentucky University Libraries. His contributions to ATG are invaluable, and his review of Intellectual Property and Competition adds to his impressive body of work.

James Williams, III, Assistant Dean for Public Services at the College of Charleston's Addlestone Library, earned his BA in Philosophy from the College of Charleston and his MLIS from the University of South Carolina. Lucky for me, I shared an office with James for several years and can claim first-hand knowledge of his expertise in staff development (among other professional areas). He is indisputably a knowledgeable, engaged, and all-around kind library leader - and therefore offers a voice of experience in his examination of An Introduction to Staff Development in Academic Libraries.

Many, many thanks for Bryan and James. Happy conferencing and happy reading, everyone! $-\boldsymbol{D V}$

\section{Carrier, Michael A., ed. Intellectual Property and Competition. Cheltenham, UK:} Edward Elgar, 2011. 978-1-84844-218-4. 776 pages. \$375.00.

Reviewed by Bryan M. Carson (Special Assistant to the Dean for Grants and Projects and Coordinator of Reference and Instructional Services, Western Kentucky University Libraries) <bryan.carson@wku.edu>

$\mathrm{T}$ he intersection between intellectual property law and competition is one of the most important - but most neglected - topics in the field. How do you reconcile freedom of the marketplace and antitrust laws with the exclusive rights granted to owners of intellectual property? Intellectual Property and Competition, edited by Michael A. Carrier, contains a mixture of classic and newer articles dealing with the issues and potential conflicts raised by the overlap of these two separate fields.

There is a debate in the library world over what to do with compilations of previouslypublished materials. Should we purchase these for our collection? Or should we consider them redundant and instead direct our clients to view the original articles? The answer to this question often depends on what type of library you represent and on the depth of your journal holdings. Of course, it also depends on the richness of the articles selected by the compilation editor.

In the case of Intellectual Property and Competition, Michael Carrier has selected a variety of articles by some of the most distinguished and forward-thinking scholars in the field. In fact, a perusal of the table of contents reads like a Who's Who of IP-Competition scholars: Herbert Hovenkamp, Richard Posner, Robert Pitofsky, and Carl Shapiro. Although many of the articles were published between 2000 and 2002, these authors are so advanced in their analysis that mainstream scholarship has only now caught up. For example, Carl Shapiro's 2000 work 'Navigating the Patent Thicket: Cross Licenses, Patent Pools, and Standard Setting," is very heavily cited. (This chapter was originally published in Volume 1 of Innovation Policy and the Economy). There are also a number of classic articles, such as William F. Baxter's influential 1966 work "Legal Restrictions on Exploration of the Patent Monopoly: An Economic Analysis" (originally published in the Yale Law Journal).

The collection starts with Herbert Hovenkamp's historical analysis, "The Conflict between Antitrust and Intellection Property Rights" (originally a 2005 chapter in The Antitrust Enterprise: Principle and Execution). Richard A. Posner and Robert Pitofsky contribute articles on the new economy. Several articles deal with global approaches, and the editor has selected material covering patent pools, unilateral refusals to license, the pharmaceutical industry, and standards-setting organizations.

The work in this volume is outstanding, and still retains its cutting-edge quality. In terms of whether to purchase this volume or rely on the originals, I recommend that it be purchased by law firms dealing with either antitrust or intellectual property issues. While academic law libraries will probably have most of the original material, firms probably will not. Similarly, some universities supporting Ph.D.-level economics programs (but not law schools) might find the work useful. Also, it would be useful for specialized or medical research institutions that create lots of patents. Intellectual Property and Competition is highly recommended for these types of collections.

continued on page 68 